\title{
Myasthenia Gravis with Membranous Nephropathy, Successfully Treated with Extended Total Thymectomy
}

\author{
Masayuki Matsuda, Jun Miki, Ken-ichi Tabata, Masaya Ikezoe*, \\ Nobuhiro NISHIZAWA ${ }^{* *}$ and Hiroki ISHIGAME***
}

\begin{abstract}
A 46-year-old woman showed proteinuria and hematuria after left blepharoptosis, and revealed a histopathology of membranous nephropathy (MN) at renal biopsy. She was diagnosed as having myasthenia gravis (MG) because of a positive edrophonium test and anti-acetylcholine receptor (AchR) antibodies in serum. We found a decrease in antiAchR antibodies after extended total thymectomy, in parallel with an improvement in both urinary findings and myasthenic symptoms. In this case, MG preceded MN and the thymectomy was effective for both diseases, suggesting that the thymus might play an important role in the pathogenesis of MN.
\end{abstract}

(Internal Medicine 39: 490-494, 2000)

Key words: anti-acetylcholine receptor antibody, renal biopsy, hepatitis B virus carrier

\section{Introduction}

Myasthenia gravis (MG) is known to be associated with various kinds of immunological diseases. In recent years, several patients with $\mathrm{MG}$ and glomerulonephritis have been reported (1-8), drawing attention to a possible link between the two diseases. Here, we report a patient with MG and membranous nephropathy $(\mathrm{MN})$, successfully treated by extended total thymectomy.

\section{Case Report}

A 46-year-old woman with no significant family history had been followed as a hepatitis B virus (HBV) carrier at our hospital since the age of 25. In August 1995 she started to experience blepharoptosis in the left eye but did not visit the hospital. Because proteinuria and microhematuria were detected at a routine annual medical examination in October 1996 she was examined at the Department of Nephrology at our hospital, and showed normal renal function with urinary protein excretion of $0.6 \mathrm{~g} / \mathrm{day}$. A percutaneous renal biopsy performed in January 1997 demonstrated a histopathology compatible with MN. No abnormal findings were detected in abdominal ultrasonography, endoscopy of the upper gastrointestinal tract, and occult blood in the stool. In spite of anti-hypertensive drugs, she showed poor control of blood pressure and an increase in urinary protein excretion ( $2.2 \mathrm{~g} /$ day) with hypoalbuminemia, which led us to treat her with oral prednisolone at a dose of 40 $\mathrm{mg}$ /day in December 1997. The daily dose of prednisolone was tapered gradually from January 1998 because of prompt response, with a urinary protein excretion below $0.2 \mathrm{~g} /$ day. In August 1998 she showed an increase in hepatic enzymes in serum and seroconversion of hepatitis B envelope (HBe) antigen possibly due to a reactivation of $\mathrm{HBV}$, resulting in an acceleration of the tapering speed for prednisolone with an exacerbation of the blepharoptosis. She was admitted to the Department of Neurology in January 1999 because of acute development of bilateral blepharoptosis with easy muscular fatigability after cessation of oral prednisolone at the end of 1998 .

On admission, her blood pressure was $161 / 111 \mathrm{mmHg}$. She showed bilateral blepharoptosis, more prominent on the left side, and proximal muscle weakness of the upper extremities with easy muscular fatigability. All deep tendon reflexes were normal. There were no abnormal findings in routine laboratory data including hematology, blood chemistry and thyroid function. Urinalysis revealed strongly positive proteinuria and microhematuria with urinary protein excretion of $1.0 \mathrm{~g} /$ day. In the examination for $\mathrm{HBV}$, hepatitis B surface (HBs) antigen was positive, and both $\mathrm{HBe}$ and hepatitis $\mathrm{B}$ core $(\mathrm{HBc})$ antigens were negative. Electromyogram with repetitive stimulation, edrophonium test, and the detection of anti-acetylcholine receptor (AchR) antibodies $(26 \mathrm{nmol} / l)$ in serum confirmed the diagnosis of MG. Anti-nuclear antibodies were also present $(\times 320)$, but anti-striated muscle antibodies, anti-DNA antibodies, rheumatoid factor, cryoglobulin and immune complexes

From the Department of Neurology, *the Department of Nephrology, **the Department of Surgery and ***the Department of Clinical Pathology, Saku Central Hospital, Usuda

Received for publication September 7, 1999; Accepted for publication January 4, 2000

Reprint requests should be addressed to Dr. Masayuki Matsuda, the Department of Neurology, Saku Central Hospital, 197, Usuda, Usudamachi, Minamisakugun, Nagano 384-0301 
were all negative. A computed tomography scan showed no abnormal mass in the anterior mediastinum.

In a reexamination of the specimen taken at the renal biopsy, histology showed a diffuse thickening of the basement membrane and a spike formation (Fig. 1), corresponding to subepithelial immune deposits in electron microscopy (Fig. 2). Immunofluorescent microscopy demonstrated positive stain-

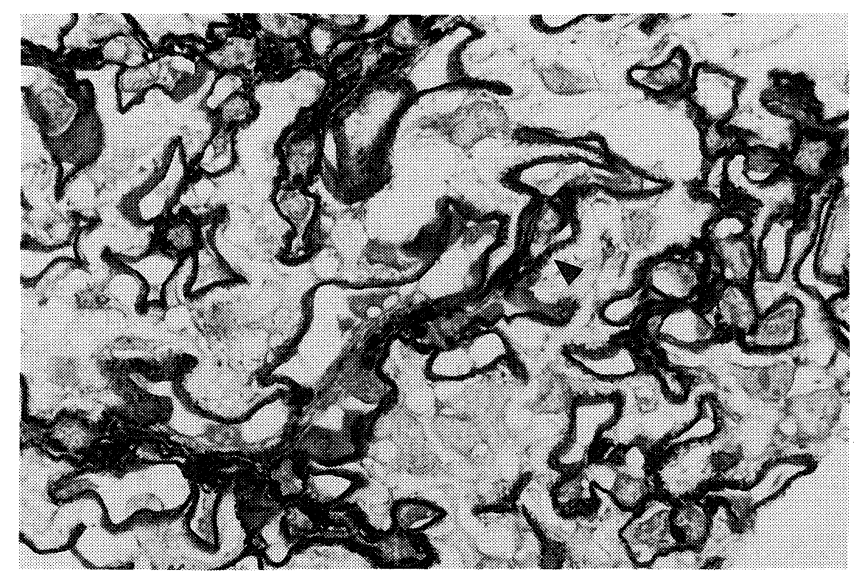

Figure 1. Histology shows a diffuse thickening of the basement membrane and a spike formation (periodic acid methenamine silver stain, $\times 470$ ). ing in a granular pattern for $\operatorname{IgG}, \operatorname{IgA}$ and $\mathrm{C}_{3}$ (Fig. 3), but it was negative for IgM, $\mathrm{C}_{1 \mathrm{q}}$, fibrinogen and $\mathrm{HBV}$-related antigens (HBs, $\mathrm{HBe}, \mathrm{HBc}$ ).

After discharge from our hospital her symptoms did not improve much in spite of the administration of ambenonium. In February 1999 an extended total thymectomy was performed at the Department of Surgery in our hospital; lymphoid hyper-

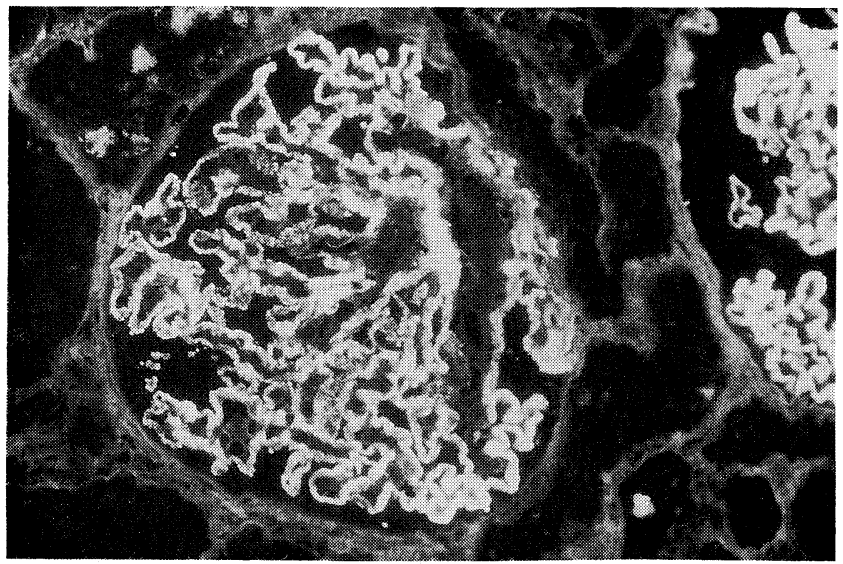

Figure 3. Immunofluorescent microscopy demonstrates positive staining for IgG along the capillary wall in a granular pattern $(\times 240)$.

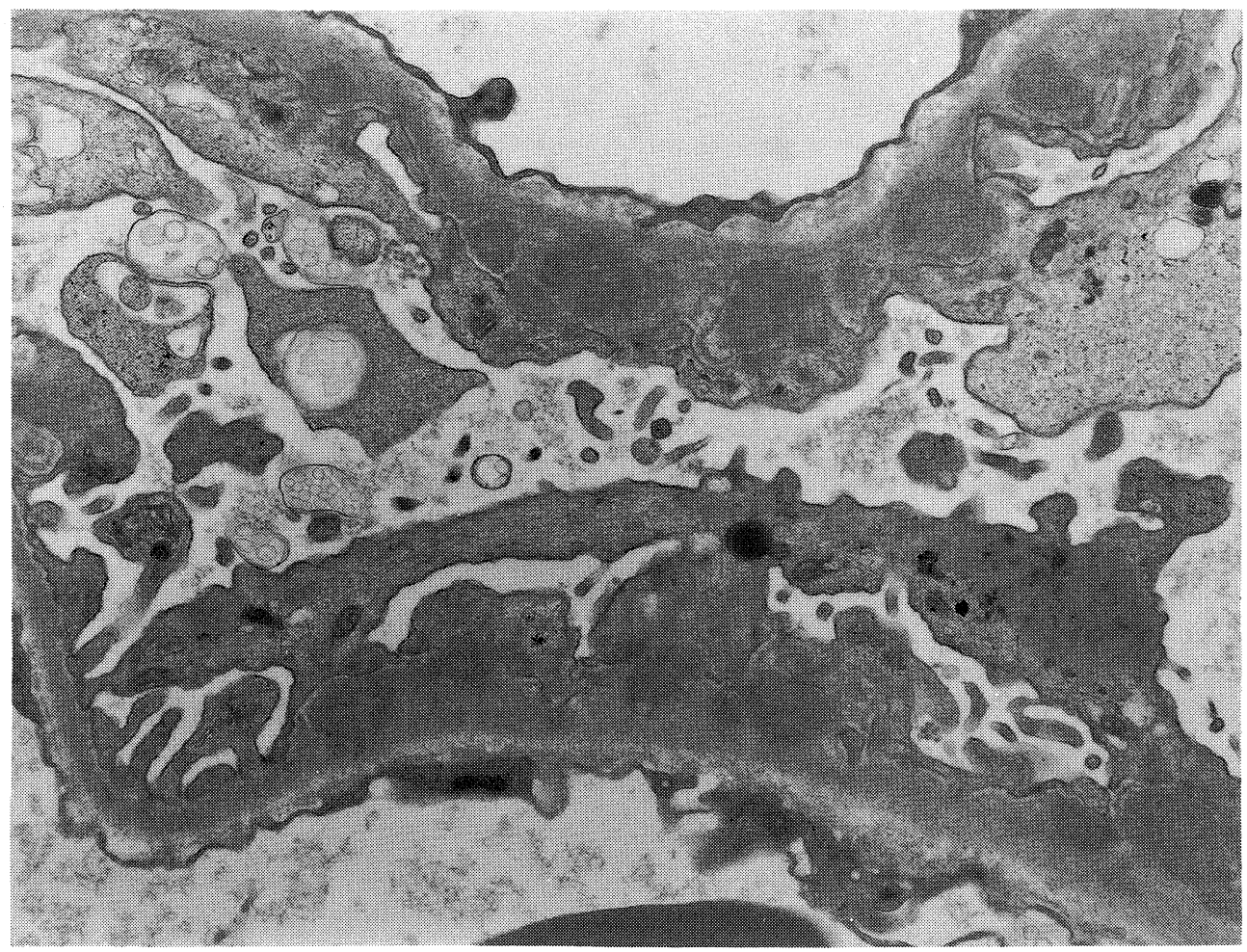

Figure 2. In electron microscopy, the subepithelial space of the glomerular basement membrane is widened and occupied by electron-dense deposits $(\times 12,000)$. 


\section{Matsuda et al}

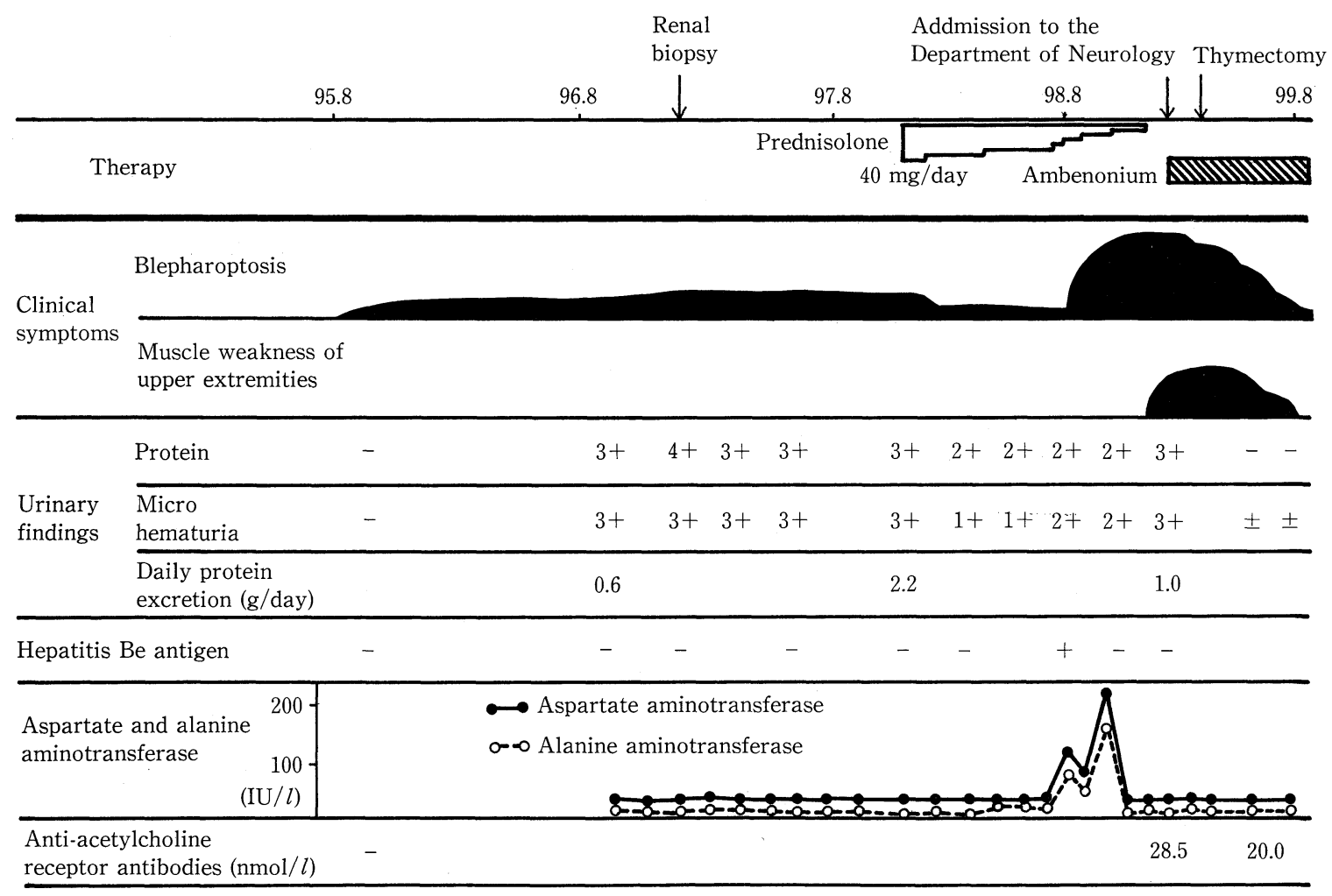

Figure 4. Clinical course.

plasia was seen in the dissected tissue. The blepharoptosis and weakness of the upper extremities improved gradually with the administration of ambenonium after the thymectomy. In June 1999 laboratory data showed negative protein and faintly positive occult blood in urine with anti-AchR antibodies decreased to $20 \mathrm{nmol} / l$ in serum (Fig. 4).

\section{Discussion}

This case presented with blepharoptosis during observation as an HBV carrier and showed proteinuria and microhematuria in a routine medical examination one year and two months after the onset of MG. The absence of abnormal findings in urinalysis performed at the onset of the blepharoptosis confirmed that MG preceded the renal disease. After she was diagnosed as having $\mathrm{MN}$ based on the findings of renal biopsy she was treated with oral prednisolone, and showed an improvement in both the blepharoptosis and urinary findings. Her myasthenic symptoms were exacerbated during the tapering of prednisolone due to reactivation of $\mathrm{HBV}$ with an increase in hepatobiliary enzymes in sera. At admission she was considered to have grade II MG (mild, generalized) according to modifications of the Osserman scale (9) because she showed easy muscular fatigability of the upper extremities and bilateral blepharoptosis without bulbar palsy. The most chacteristic point of this case is that thymectomy was effective for both MG and $\mathrm{MN}$, suggesting that these diseases might have a common im- munological basis pathogenetically. There are three possible factors which might contribute to the induction of both MG and MN: HBV infection, autoantibodies including anti-AchR antibody, and the thymus.

Neurological symptoms in patients with HBV-related hepatitis can be ascribed not only to the side effects of drugs used for treatment, including interferon (10), but also to HBV itself, as exemplified by polyneuropathy due to the deposition of immune complexes $(11,12)$. According to McFarlane et al, antibodies against hepatic asialoglycoprotein receptor, which have molecular analogy with AchR, can be detected in sera of patients with either autoimmune or HBV-related chronic active hepatitis (13). However, whether these antibodies can react with AchR pathogenetically remains unclear. On the other hand, it is well known that MN is frequently associated with HBV infection including its carrier (14). Several reports demonstrated that renal tissues taken at renal biopsy showed $\mathrm{HBc}$ and $\mathrm{HBe}$ antigens in immune deposits along the capillary wall in $\mathrm{MN}$ associated with $\mathrm{HBV}$ infection, indicating that these HBV-related antigens can induce the glomerular lesions (15, 16). In this case, both $\mathrm{HBe}$ and $\mathrm{HBc}$ antigens in sera were consistently negative with normal values of hepatobiliary enzymes, except for a short period with oral prednisolone, and immunofluorescent microscopy revealed no HBV-related antigens including $\mathrm{HBs}, \mathrm{HBc}$ and $\mathrm{HBe}$ in renal tissues taken at the biopsy. This suggests that there is no cause-effect relationship between MN and HBV infection. 
The second possible factor which may induce both MG and MN is autoantibodies including anti-AchR antibody. Circulating anti-AchR antibodies, which are found in MG patients, may also react against glomerular antigens, thus causing complement fixation, activation of the lytic phase of complement reaction, and membrane attack deposition as they do in the neuromuscular junction (17). Alternatively, the same events might be caused by immune complexes containing anti-AchR antibodies or other autoantibodies. Although we could not find immune complexes in sera in this case, both MG and MN improved after thymectomy, with a corresponding decrease in circulating anti-AchR antibody. This result suggests that autoantibodies including anti-AchR antibody might play an important role in the pathogenesis of both MG and MN.

Another possible factor inducing the association with $\mathrm{MN}$ may be an impairment of cellular immunity due to the thymus gland lesion, because several cases of glomerulonephritis have been described in patients with thymoma without MG (18-21) and in those with a long interval after thymectomy $(2,4,7)$. Thymectomy, which is a standard therapy for MG, is known to lead to autoimmune diseases (22), as exemplified by systemic lupus erythematosus (23) and anti-phospholipid syndrome (24). In the present case, MG preceded MN and the thymectomy was effective for both diseases, suggesting that the thymus might contribute to the pathogenesis of MN. Recently, several reports suggest that $\mathrm{IgG}_{4}$ is related predominantly to glomerular deposition in $\mathrm{MN}$ based on immunohistological studies, because $\mathrm{IgG}_{4}$ cannnot fix complements with a low affinity for $\mathrm{Fc}$ receptors, thus making $\mathrm{IgG}_{4}$-containing complexes easy to dissociate and traverse the glomerular-basement membrane with an impaired clearance $(25,26)$. The profile of immunoglobulin isotypes is heavily influenced by the balance of two different subsets of $\mathrm{T}$ helper cells (Th1 and Th2) in the immune response. Because the $\mathrm{IgG}_{4}$ switching is induced by $\mathrm{Th} 2$ responses (27), the thymus might relate to the induction of $\mathrm{MN}$ in controlling Th1/Th2 balance.

As far as we know, fifteen adult cases of MG associated with glomerulonephritis (non-drug induced) have been described in recent years (1-8). MG usually preceded glomerulonephritis, although in four cases the glomerulonephritis developed first $(1,3)$, and in another patient the renal disease and MG were diagnosed at the same time (6). Histopathologically, there were four cases of IgA nephropathy, three cases of minimal change and $\mathrm{MN}$, and five cases of other glomerulonephritis. Considering that just three of fifteen reported cases showed complete remission after therapy $(2,4,8)$, the prognosis of the renal diseases associated with MG is generally not very good in spite of treatment with prednisolone and immunosuppressive drugs. Because we were unable to treat this case in the long term with either oral prednisolone or immunosuppressive drugs because she was an HBV carrier, we decided to perform thymectomy, which produced good effects for both the MG and MN. Thymectomy is followed by numerous changes in lymphocyte functions which may require several years to fully be revealed (28), suggesting that careful follow-up for a long period is necessary.
Acknowledegments: The authors thank Mr. S. Yoshimoto, Saku Central Hospital, for help in praparing the manuscript.

\section{References}

1) Endoh $M$, Kaneshige $H$, Tomino $Y$, et al. IgA nephropathy associated with myasthenia gravis and scleritis. Tokai J Exp Clin Med 6: 421-425, 1981.

2) Scadding GK, Sweny P, Wilson SG, Havard CW, Newsom-Davis J. Glomerulonephritis, thymoma and myasthenia gravis. Q J Med 52: 187-193, 1983.

3) Miyazaki M, Kimura N, Imai K, et al. Association of IgA nephropathy and myasthenia gravis. Nephron 51: 402-404, 1989.

4) Chan PC, Lau CC, Cheng IK, Chan KW, Jones BM, Chan MK. Minimal change glomerulopathy in two patients after thymectomy. Singapore Med J 31: 46-47, 1990.

5) Innes A, Cotton RE, Burden RP. Association of IgA nephropathy and myasthenia gravis. Nephron 54: 354, 1990.

6) Haslam PJ, Proctor SJ, Goodship TH, Zouvani J. Immune complex glomerulonephritis, myasthenia gravis and compensated hypothyroidism in a patient following allogeneic bone marrow transplantation. Nephrol Dial Transplant 8: 1390-1392, 1993.

7) Valli G, Fogazzi GB, Cappellari A, Rivolta E. Glomerulonephritis associated with myasthenia gravis. Am J Kidney Dis 31: 350-355, 1998.

8) Tomida $\mathrm{C}$, Yamagata $\mathrm{K}$, Ishizu $\mathrm{T}$, et al. A case of nephrotic syndrome associated with myasthenia gravis and malignant thymoma. Nippon Jinzo Gakkai Shi 41: 77-82, 1999.

9) Drachman DB, Kuncl RW. Myasthenia gravis. in: Immunology of Neuromuscular Disease. Hohlfeld R, Ed. Kluwer Academic Publishers, Dordrecht, 1994: 165-207.

10) La Civita L, Zignego AL, Lombardini F, et al. Exacerbation of peripheral neuropathy during alpha-interferon therapy in a patient with mixed cryoglobulinemia and hepatitis B virus infection. J Rheumatol 23: 1641-1643, 1996.

11) Tsukada N, Koh CS, Owa M, Yanagisawa N. Chronic neuropathy associated with immune complexes of hepatitis B virus. J Neurol Sci 61: 193210, 1983.

12) Tsukada N, Koh CS, Inoue A, Yanagisawa N. Demyelinating neuropathy associated with hepatitis B virus infection. Detection of immune complexes composed of hepatitis B virus surface antigen. J Neurol Sci 77: 203-216, 1987.

13) McFarlane BM, McSorley CG, Vergani D, McFarlane IG, Williams R. Serum autoanitibodies reacting with the hepatic asialoglycoprotein receptor protein (hepatic lectin) in acute and chronic liver disorders. J Hepatol 3: 196-205, 1986.

14) Lai KN, Lai FM, Tam JS. Comparison of polyclonal and monoclonal antibodies in determination of glomerular deposits of hepatitis B virus antigens in hepatitis B virus-associated glomerulonephritides. Am J Clin Pathol 92: 159-165, 1989.

15) Lin CY. Hepatitis B virus-associated membraneous nephropathy. Clinical features, immunological profiles and outcome. Nephron 55: 37-44, 1990.

16) Takekoshi $Y$, Tochimaru H, Nagata $Y$, Itami N. Immunopathogenetic mechanisms of hepatitis B virus-related glomerulopathy. Kidney Int Suppl 35: S34-S39, 1991.

17) Fazekas A, Komoly S, Bozsik B, Szobor A. Myasthenia gravis. Demonstration of membrane attack complex in muscle end-plates. Clin Neuropathol 5: 78-83, 1986.

18) Varsano S, Bruderman I, Bernheim JL, Rathaus M, Griffel B. Minimalchange nephropathy and malignant thymoma. Chest 77: 695-697, 1980.

19) Ogawa $M$, Ueda $S$, Ohto $M$, et al. Minimal change nephrotic syndrome developed after non-surgical treatment of a thymoma. Clin Nephrol 38: 171-172, 1992.

20) McDonald P, Kalra PA, Coward RA. Thymoma and minimal-change glomerulonephritis. Nephrol Dial Transplant 7: 357-359, 1992.

21) Posner MR, Prout MN, Berk S. Thymoma and the nephrotic syndrome. A 


\section{Matsuda et al}

report of a case. Cancer 45: 387-391, 1980.

22) Weinberg K, Parkman R. Age, the thymus, and T lymphocytes. N Engl J Med 332: 182-183, 1995.

23) Mevorach D, Perrot S, Buchanan NM, et al. Appearance of systemic. lupus erythematosus after thymectomy. Four case reports and review of the literature. Lupus 4: 33-37, 1995.

24) Shoenfeld Y, Lorber M, Yucel T, Yazici H. Primary antiphospholipid syndrome emerging following thymectomy for myasthenia gravis. Additional evidence for the kaleidoscope of autoimmunity. Lupus 6: 474-476, 1997.

25) Imai H, Hamai $K$, Komatsuda A, Ohtani H, Miura AB. IgG subclasses in patients with membranoproliferative glomerulonephritis, membranous nephropathy, and lupus nephritis. Kidney Int 51: 270-276, 1997.

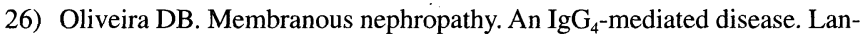
cet 351: 670-671, 1998.

27) Holdsworth SR, Kitching AR, Tipping PG. Th1 and Th2 T helper cell subsets affect patterns of injury and outcomes in glomerulonephritis. Kidney Int 55: 1198-1216, 1999.

28) Wijermans P, Oosterhuis HJ, Astaldi GC, Schellekens PT, Astaldi A. Influence of adult thymectomy on immunocompetence in patients with myasthenia gravis. J Immunol 124: 1977-1982, 1980. 